\title{
Transitions in Old Age: The Meanings of Body from the Perspective of Older Adults with Acquired Impairment*
}

\author{
TATIANA SEDLÁKOVÁ and MARCELA PETROVÁ KAFKOVÁ** \\ Faculty of Social Studies, Masaryk University, Brno
}

\begin{abstract}
This paper summarises the knowledge about transition from the third age to what is called the fourth age. The study understands ageing as an embodied process and explores the meanings that are attached to the body in the narratives of older persons who have acquired impairment in later life and are receiving care. Because the onset of impairment and infirmity marks a point of transition, the study considers the bodily aspects of the ageing process as key elements, despite this being highly problematic in current social gerontology. The authors call for a complex approach to understanding the meanings of the body in the transitions into old age and drawing on their own study based on three repeated interviews with ten older adults conducted over the course of one year ( 8 women, mean age $=83.8$ years), they explore the meanings that are attached to the body in the context of receiving care. Their analysis of the personal accounts and narratives of everyday activities from the participants in their study revealed that embodiment in action is the main topic through which participants experienced their everydayness. The meanings of embodiment in action are shaped and reconstructed on three dimensions that capture important processes of embodiment in action: the sensing of the body (the Body as an Organiser of Activities), anticipation of the body (the Body as an Uncertain Companion), and the managing of the body (the Body as Work to Be Done). The findings offer insights into the processes of transitions in old age, in which the emotional, social, and behavioural aspects of embodiment in action, rather than age, play the key role. The study further highlights that the meanings of the body are complex, highly relevant, and should not be overlooked within the organisational practice of social and health care.
\end{abstract}

Keywords: fourth age, body, transitions, acquired impairment, repeated interviews, meaning of the body

Sociologický časopis/Czech Sociological Review, 2021, Vol. 57, No. 3: 315-342

https//doi.org/10.13060/csr.2020.032

\footnotetext{
* This paper was prepared as part of work on the research project 'Fourth Age: The Identity of Disability During the Period of Active Ageing' supported by the Czech Science Foundation (GA15-03156S).

** Direct all correspondence to: Marcela Petrová Kafková, Department of Sociology, Faculty of Social Studies, Masaryk University, Joštova 10, Brno 60200, Czech Republic, e-mail: kafkova@fss.muni.cz.
}

(C) Sociologický ústav AV ČR, v. v. i., 2021

(C) Authors, 2021 


\section{Introduction}

A focus on longevity has become an integral part of professional and public debates, especially in Western societies. These debates have resulted in a polarised understanding of old age, dividing it into an independent active phase and a dependent passive phase. While the former is characterised by ideas of agelessness and increasingly new possibilities, the latter calls to mind biological decline, solitude, and ultimately death [Featherstone and Hepworth 1989; Neugarten 1974; Stuart-Hamilton 2006]. All these divisions, including the developmental concepts of 'later adulthood' and 'elderhood' [Newman and Newman 2015], use age as their defining criterion. However, the meaning of age has changed in the contemporary context and, as a result, the current models with which we make sense of the life course are shifting away from age- and stage-based concepts. Contemporary readings suggest that transitions in old age may be organised along completely different lines of experience than age [Gubrium and Holstein 2003; Grenier 2015]. Impaired bodily functions and chronic illness, for example, are good examples of a transition that destabilises age- and stage-based notions at the foundation of social gerontology. According to Grenier [2015], it is the uncertainty, timing, and severity of chronic illness that challenges fixed notions of age and chronometric time. The illness and resulting impairment may be more cyclical and temporary in nature, may occur earlier than expected (e.g. due to lifelong hard manual labour), may involve moments of recovery and re-occurrence, and may create a disconnect between older people's experiences and social and cultural constructs of health and illness in later life [e.g. Laslett 1991]. Consequently, the transitions in old age are more dynamic and fluid than the fixed stages of development situated across a linear life course. The body seems to be the central entity through which people experience these transitions.

The most extensive theoretical work on forms of old age has been done by developmental psychologists Baltes and Smith [2003] and cultural gerontologists Higgs and Gilleard [2015, 2016]. Both pairs of scholars have continued to build on the concepts of the third and fourth ages that were first developed by Laslett [1991]. According to Baltes and Smith [2003], the fourth age is a stage of the life cycle that combines at least two characteristics: a chronological age of 75+ and the disintegration of self-management skills due to age-related physical limitations. This state is accompanied by reduced potential for improving functions and sometimes even by psychological mortality, i.e. various degrees of loss of identity, autonomy, and self-control. The former characteristic is emphasised and therefore the concept of the fourth age is reduced almost entirely to its age-based definition. Gilleard and Higgs [2011, 2013] understand the fourth age as a social imaginary or a social representation of a specific but not inevitable form of old age that is defined in terms of a loss of independence resulting from impairment, which is then replaced by institutional care. As reported by these authors, there are four elements that underpin much of the social imaginary of the fourth age: frailty, abjection, the loss of agency, and conditions of care [Higgs and Gilleard 2016]. They also understand it as a cultural location stripped of the social and 
cultural capital that used to allow for the articulation of choice, autonomy, selfexpression, and pleasure in later life [Gilleard and Higgs 2010]. To sum up, the constructs of the fourth age are defined around the ideas of advanced age, the impairment of bodily functions, and the conditions of care. The concept of the fourth age is defined on different levels and takes place at the intersections of the body and ageing.

The distinction between the third age and the fourth age can be presumed to be qualitative in nature. The ideas that inform the transitions between these two forms of old age are moreover accompanied by deeply ingrained ideas of success and failure [Grenier 2012, 2015]. Bodily impairment in later life is one of the factors (others include, e.g., poverty, a different approach to activities) that often prevent people from fulfilling the socially desirable 'ideal' of an active third age. Consequently, representations of the fourth age often remain unrecognised and invisible. This study relies on the accounts of older adults with acquired impairment in later life and seeks to understand the meanings of the body during transition processes in later life. The context of the body is not understood a priori through a perspective of limitations on the side of the older adults, but rather relationally as the constellation of different possibilities on the side of researcher and research participant [Sedláková and Souralová 2017].

The objective of the study is to explore how individuals whose lives are affected by an acquired impairment and by the need for care see and understand their own body. Drawing on personal accounts and narratives of the everyday activities and routines of such individuals, the article has two main aims: First, to describe the meanings that the participants with acquired impairment in later life ascribe to their bodies. Second, to analyse the ways in which they emotionally, socially, and behaviourally relate to these meanings of the body. As the construction of the fourth age cannot be fully understood without considering the care context [Higgs and Gilleard 2016; Petrová Kafková and Sedláková 2017], we put the emphasis on the narration of activities in which the participants receive care from others.

To fulfil these aims, the article is divided into theoretical sections, where we introduce the philosophical and conceptual backgrounds and present the findings from current studies that have sensitised the process of our exploration [Charmaz 2014; Strauss and Corbin 1990]. In the later methodological part, we introduce the approach we used to create and analyse data. Later, we present the main findings that are presented through the narrative of the working model. Finally, in the discussion part, we present the most important findings, emphasise their reconnections with previous knowledge, and pose some questions that could direct future research in this field. The findings of this study represent an empirical contribution to the discussion among scholars in social gerontology and ageing studies about the role of embodiment in old age, specifically during the transitions in old age. They also provide insight into the development of useful interventions that could promote more respectful and mindful approaches within the context of long-term care. 


\section{The complexity of the body as the central entity of experience in advanced age}

There is no doubt that ageing is an embodied process. However, the importance of recognising the centrality of the body in the ageing process was not understood in its complexity until recently [Shilling 2007]. As feminist scholars [e.g. Twigg 2004] have pointed out, bodies have until recently been studied mostly from the perspective of the natural sciences and comprehended through biomedical discourse, solely as passive victims of decline and a burden to others. The main reason for such a one-sided biological understanding of the body was the ontological dualism between the body and the mind that has formed the epistemological basis of knowledge in western societies [Shilling 2007; Twigg 2004; Twigg and Martin 2015]. The predominance of Cartesian distinctions is still deeply rooted in both gerontological conceptual thinking and empirical practice. One such example is the research topic of aged identities, which focuses on the discrepancies and tensions between the external appearance of the body and an internal (youthful) identity. According to the Mask of Ageing Thesis [Biggs 1997; Featherstone and Hepworth 1991], even older people who are experiencing age-related illnesses say that they don't feel old and they perceive their visibly old bodies as a mask concealing an ageless and thus more valuable self [e.g. Heikkinen 2004; Jolanki 2009]. The status of bodily ageing in these approaches is pivotal, but it refers mostly to the negotiations of third-age identities, dealing with the perception of the appearance of the aged body and contrasting it with the youthful self of the ageing subject. Indeed, the body must eventually show its age, a harbinger of what Gilleard and Higgs [2010] call the fourth age, the age of extreme age and disability.

In social gerontological research, the ageing body has recently been addressed more complexly [Gubrium Holstein 2003; Öberg 1996, 2003; Twigg 2004, 2006]. A large body of literature has focused on body image in a consumer-based culture [Clarke and Korotchenko 2011] and sometimes on the bodies of people with dementia [Phinney and Chesla 2003]. Twigg [2006] emphasises that various other aspects of the body and embodiment are still neglected. Despite increased longevity, marginalised and 'problematic' bodies remain in a peripheral position. One of the reasons may be that the attempt to emphasise the body in this context can (to many) seem like a retrogressive step - one that takes us back onto the territory of biological determinism and the narrative of decline, depicting older people's bodies as simply frail and dependent. However, the aim of this study is to overcome this determinism and to deal with the meanings of the body in its complexity. As stated in our previous work, we seek to avoid the objectifying attitudes towards aged bodies, which approach old age from the perspective of an outsider or solely from proxy accounts of formal or informal caregivers [Sedláková and Souralová 2017]. Like Grenier, Lloyd and Phillipson [2017], the authors of this study understand the fourth age as a state that is based on relational autonomy and that requires the recognition of shared vulnerability and responsibility for care.

The study further uses the concept of 'embodiment', which is understood 
to mean the experience, the gathering thoughts and feelings, and behaviours grounded in the bodily interaction with the environment. Embodiment further captures the complex and dynamic nature of the body, acknowledging its material specificities, but also its social, emotional, and behavioural aspects. In contrast to Cartesian dualism, the embodiment approach understands the body and mind as fused so that they form a single entity [Meier et al. 2012]. Sandberg writes in an article [2013] that the material body should be regarded as possessing the force and agency to shape subjectivity and sociality, and not just as a malleable raw material that is shaped by sociocultural discursive regimes. She follows Grosz's non-binary approach to embodiment and argues for an 'affirmative old age' that is based on an integrated body and mind relationship and underlines the facticity of the ageing body. Grosz [1994] conceptualises the body as an 'open materiality' that is neither a culturally inscribed product of the social world nor simply a part of biology or nature. Instead, the body as an open materiality exists as a borderline between the binary poles of the natural and cultural dichotomy.

\section{The meanings of the body during the transition into old age}

Although social gerontology has been criticised in the past for failing to acknowledge bodily ageing and for neglecting the body experience of ageing subjects, there are some studies that deal on the whole [e.g. Grenier 2008; Nicholson et al. 2012, 2013; Phinney and Chesla 2003; Sandberg 2013; Witaker 2010] or in part [e.g. José 2016; Heikkinen 2000, 2004; Lloyd et al. 2016; Pirhonen et al. 2015] with the meanings of the body and the embodiment of older adults with impairment. Most of these studies have gone beyond examining how bodies are perceived and managed in everyday life and focus on how the ageing process is embodied and how age is accomplished. These works further examine how older adults experience bodily changes related to impairment, chronic illness, or frailty, pointing out the meanings and experiences and some strategies for older adults to incorporate bodily changes into their everyday lives.

Some of these studies examine the day-to-day experiences of participants whose lives are affected by receiving care. They focus on the topics of dignity [José 2016; Lloyd et al. 2016] and autonomy in later life [Pirhonen et al. 2015]. An ethnographic study by José [2016] detected five modes of maintaining dignity that older adults use in the context of social care - such as sheltering in personal space, disconnecting from life, or keeping going. The behavioural pattern of 'keeping going' refers to continuous activities relating to the care of one's body and continuing to engage in previous activities with assistance from others or from assistive devices. The keeping going pattern also includes undertaking new activities with the aim of optimising the performance of the body in other activities (e.g. regular exercise in the morning). This pattern is therefore a reactive response to losses, but in some cases it is a proactive method of preventing additional losses and impairments. 
The study by Lloyd et al. [2014] examined the experience of 34 participants, aged 75 and over, whose health problems meant they required varying degrees of support and care. All participants typically described their loss of physical strength and energy as a 'slowing down process'. In addition, there was a preference for activities associated with deeply ingrained habits, which differed from cognitive thought that may have been lost due to illness, incapacity, or exhaustion. This preference was referred to by Lloyd et al. as the experience of the 'habitual body'. According to an analysis of interviews with 45 people aged 90-91 in a communal residence for senior citizens in Finland [Pirhonen et al. 2015], autonomy was a negotiable characteristic. The negotiation of personal autonomy was mentioned by older people struggling somewhere between the third and fourth ages [e.g. Lloyd et al. 2014]. According to Pirhonen et al. [2015], the autonomy of the participants in their study was subtly connected with adaptation, since participants recognised the possible future loss of agency and frequently used phrases such as 'as long as' and 'so far'.

There are a number of studies that focus on the body as the subject of their analyses [Rudman 2015; Sandberg 2013; Townsend, Godfrey and Denby 2006]. Rudman's findings [2015] on how people talk about ageing bodies as part of preparing for and moving into retirement demonstrated the centrality of the body to participants' understanding of 'oldness'. Thirty Canadians between the ages of 45 and 83 regarded, within their narratives, persons with 'old bodies' as irresponsible and further emphasised the ways in which they themselves had proactively taken up physical activities both to avoid 'oldness' and to ensure health and other youthful qualities. 'Old bodies' were also discussed in the context of neoliberal rationality as being immobile, in need of assistive devices, and as suffering, unattractive, and out of control. The reference to the 'oldness' of the body partially corresponds to the behavioural pattern of 'keeping going' found in the accounts of participants in the above-mentioned study by José [2016]. The results of both these studies indicate that those elderly people whose lives are affected by acquired impairment are often viewed by others as people who have not made a sufficient effort or have not carried out activities to maintain healthy and functioning bodies. This is true even of some people who claim that they themselves experience at least some limitations connected to an impairment. Similarly, in a study by Townsend, Godfrey and Denby [2006], older adults classified their agepeers as 'heroes' if they managed to keep going regardless of ageing, 'villains' if they had given up, and 'victims' if they had lost control of their lives due to health problems.

There are a few studies that deal with body-related topics in old age that have some characteristics of the fourth age - such as cognitive loss, frailty, and reflections on one's own mortality [Nicholson et al. 2012, 2013; Grenier 2008; Phinney and Chesla 2003; Whitaker 2010]. As noted above, the concept of frailty is usually used by health-care and social-care professionals to encompass both mental and physical infirmity and it implies both material and moral vulnerabil- 
ity [Higgs and Gilleard 2016]. Grenier [2008] explored the distinctions between the professional construct of frailty and the lived experiences of older women as described within older women's narratives. She emphasised the clash between the imposition of a medical and functional classification (being frail) and the emotions related to impairment, traumatic events and maintaining a continuous identity (feeling frail). Grenier also highlighted the emotional aspects of what professionals know as frailty and described the emotions involved in adjusting to uncertainty and loss and some people's thoughts of injury and death (e.g. fear, sadness, anger, rejection and many others). For participants of this study, 'feeling frail' was a negotiated state that served as a protective mechanism for 'becoming frail'.

Similarly, two studies by Nicholson et al. [2012, 2013] present findings on the experience of frail people aged $85+$ living at home in the UK. These experiences were gathered through repeated in-depth interviews and informed observation over the course of 17 months. The findings suggest that frailty is understood in terms of 'potential capacity'. The participants perceive their state as a combination of loss and creativity, as a state of imbalance in which they experience accumulated losses, whilst working to sustain and perhaps create new connections. One way they do this is to recognise the value of 'daily rituals' that facilitate creative connections to capacities whilst feeling frail [Nicholson et al. 2013]. In an earlier study, Nicholson et al. [2012] focus on the dying trajectories of frail older people and argue that this experience can be conceptualised as persistent liminality: a state of imbalance 'betwixt and between' active living and clinically recognised dying. To manage these ambiguities of persistent liminal space, the participants in the study constructed their own 'personal habitual routines' or 'personal scripts'. Like Lloyd et al. [2014] and Pirhonen et al. [2015], Nicholson et al. [2012] agree that the large and diverse group of older people who have an acquired impairment live in constant uncertainty, where there is often no resolution or completed transition from one state to another [cf. Grenier 2015: 2]. The researchers further conclude that the participants may find themselves living in a marginal and persistently fluid state between the third and fourth ages, with little recognition or support [Lloyd et al. 2014; Nicholson et al. 2012; Pirhonen et al. 2015].

The ethnographic fieldwork that Whitaker [2010] carried out in the ward of a nursing home explored the ways in which residents talk about and regard their own ageing and their bodies. That study emphasised the body as the central entity through which residents experience daily living and reveals five distinctive themes regarding the way in which they discuss their bodies: 'the incapable body', which is connected to emotions such as sorrow, grief, distress, shame, embarrassment, humiliation, indignity, or frustration; 'the body as an arena of care work', which deals with bodily needs and bodily dependence; 'bodily change and alienation', which describes constantly changing bodies; 'the inevitable death of the body and body stories/body wanderings', which is where the body becomes a tool for communication and medium of social and personal connections. 
In our study, we would like to develop some of Whitaker's themes and provide a better understanding of the meanings of the body for older people receiving care.

According to Grenier [2012], in an environment where success is often measured by the skills and achievements of a 'trouble-free' body, the impaired body may become an important marker of failure in later life and a marker whose role must be understood in relation to transitions. However, to understand the complexity of the body in the transitional processes of old age, it is essential to break free from the simplified dichotomy of success and failure, nature and culture, or the dichotomy of the third and fourth ages. Presumably, the body in the process of ageing is not necessarily going into a 'rapid slump of decay', which would necessarily, irreversibly, irrevocably, and quickly lead to a black darkness of conditions without any sign of agency [Gilleard and Higgs 2010]. The body is rather a constantly changing system that is reconnected with the emotional, social, and behavioural aspects of the embodiment experience of an older adult with an acquired impairment. It is precisely this instability, ambiguity, and transformation that is typical of the transition process in old age, which some social gerontologists call a 'grey in-between area' [Nicholson et al. 2012; Lloyd et al. 2014; Pirhonen et al. 2015].

The literature on the body within the context of receiving care has largely pointed to ways in which participants preserve their autonomy and dignity [José 2016; Lloyd et al. 2016; Pirhonen et al. 2015] or the ways in which participants experience their bodies in relation to the context of care that is provided mostly by health and social workers [Nicholson et al. 2012, 2013; Grenier 2008; Phinney and Chesla 2003; Whitaker 2010]. Most of these studies remain on the descriptive level and many of them neglect the possible analytical connections of the complex meanings of the body within the subjective experience of everydayness during transitions in old age. This study follows the complex approach to understanding the meanings of the body during transitions in old age and aims to further explore the embodied ageing process. Drawing on research that consisted of three repeated interviews conducted over the course of one year with ten older adults with acquired impairment, the findings are presented in the narration of a working model that depicts embodiment in the action of experiencing change.

\section{Materials and methods}

\section{Research project and data collection}

This article draws on the qualitative part of a research project titled the 'Fourth Age: The Identity of Disability during the Period of Active Ageing'. The overall aim of this was to describe and explore what is called the fourth age. Study data were collected between June 2015 and August 2016. Our research process consisted of four steps that included conducting individual interviews with both participants and their caregivers and the collection of data using supplementary 
Table 1. Description of the research process

\begin{tabular}{lcc}
\hline & Timing & Number of participants \\
\hline $\begin{array}{l}\text { Informed consent, 1st interview } \\
\text { with participants }\end{array}$ & June 2015-Aug. 2016 & 10 \\
Shared research diary & $1-3$ chosen days & 6 \\
2nd interview & after 1-3 months & 9 \\
Shared research diary & $1-3$ chosen days & 6 \\
3rd interview & after 1-3 months & 8 \\
Interview with caregivers & after 3rd interview & 9 \\
Data analysis & Aug. 2016-Dec.2017 & 10 \\
\hline
\end{tabular}

methods that helped us to build the research relationship and elicit the participants' narrations.

The first interview collected information on the narrative history of each participant's life to date and served to establish a research relationship. Where possible, we used the 'timeline technique', which served as a temporal structure in graphical form against which participants could summon and plot their recollections of everyday events and experiences [Adriansen 2012; Guenette and Marshall 2009; Sheridan, Chamberlain and Dupuis 2011]. When employing this technique, we started with the opening question: 'Having reached the age that you are, please would you tell me the story of your life, including all the recent events and experiences that are important to you personally?' This initial invitation was aimed at giving both the researcher and the participant the opportunity to look at the respondent's life from a life-course perspective and thus focus on the transitions in old age. Afterwards, we introduced the timeline, drawn according to participants at various times of the first interview, depending on the narrative flow of the participant's story and on the possibilities given by his/her impairment. The invitation was accompanied by these words: 'Using these blank pages, you, or we together, can draw a timeline of your life that expresses your life from the age of 60 to the present day and into the future.' Participants were asked to indicate a point on the timeline that represents the present time. Then we asked them to try to remember life events that they considered important and to place them somewhere on the timeline (Figure 1).

The following two interviews had a semi-structured form [Rubin and Rubin 2005] and focused on: daily activities; the care received during these activities and the participants' negotiation of their own involvement; the meanings attached to important material artefacts and assistive devices; the experience of bodily and health problems, etc. The interviews were supplemented with information provided by a shared research diary. The diary contained the 'Yester- 
Figure 1. An example of the timeline technique - a diagram of Tereza's timeline

\begin{abstract}
General comment
The diagram shows how we worked with the timeline during the interviews with

Tereza and what kind of data this technique provided us with in this particular case.

The first breaking moment in Tereza's biography was at age 55 when she retired. Further her timeline drawing captured several important moments: transitions between institutions, changes in personal life (birth and death of a family member) or other conditions related to health (falls, weight losses and gains). Through this visualisation key biographical moments were written down and both researcher and research participant could relate to them at any later stage of the interviews.
\end{abstract}

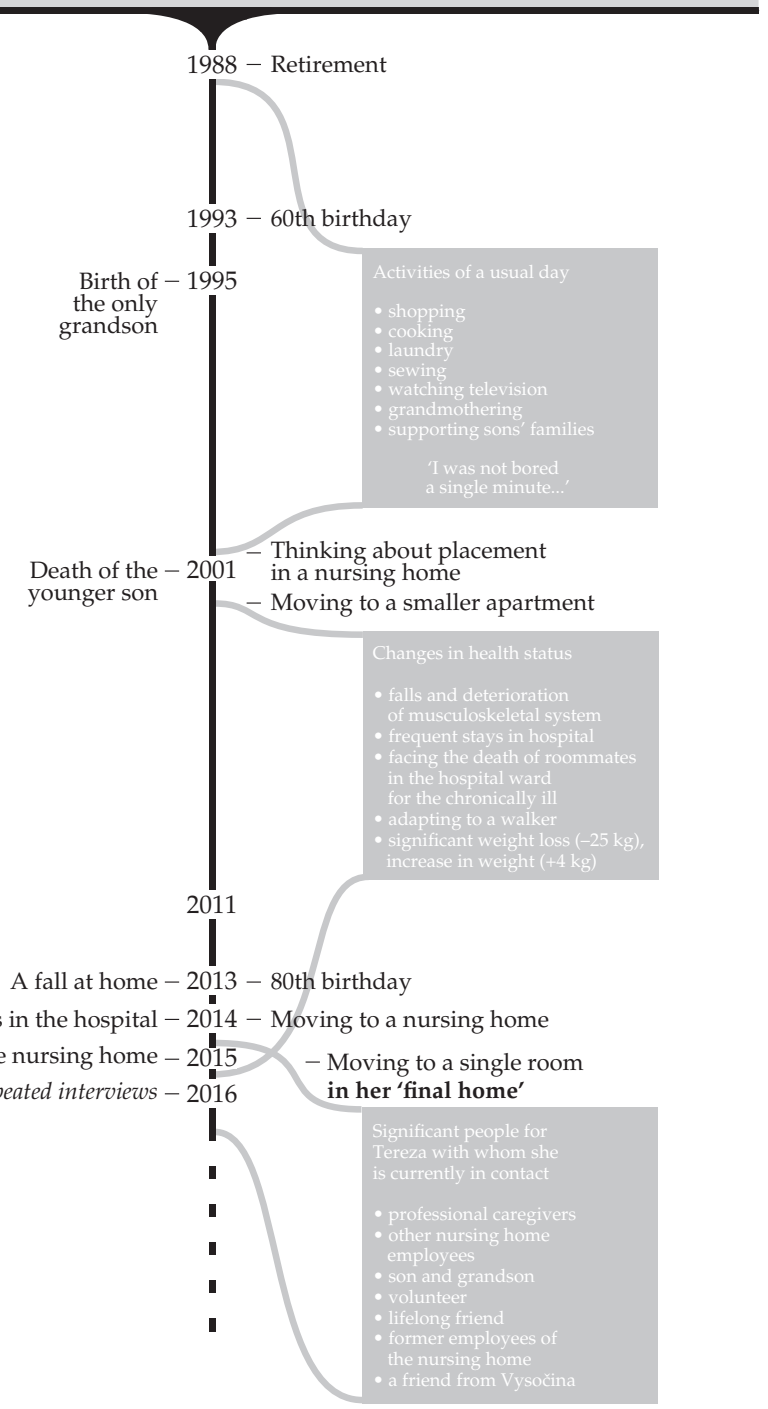


day Interview' that was used in the Berlin Ageing Study by Horgas, Wilms and Baltes [1998] and the above-mentioned timeline technique. The diary was shared between the research participant and the researcher and remained in the household of the participant for the duration of the research project, and the participant was able to add notes and ideas to it and prepare for future interviews. During the research process, the bodies of our participants were a constantly present part of the interview, not only as its topic but also as a part of a lived experience through body language [Sedláková and Souralová 2017]. The primary objective of the repeated interviews was not depiction in time, the time gap between the interviews was too short for this (and a three-year research project does not allow for a sufficiently longitudinal framework). The reason for the repeated meetings was to gain a deeper insight into and understanding of the fourth age experience and to establish a more intimate relationship with the participants and also to accommodate the fact that they could grow tired somewhat quickly and this meant the interview could not last for hours.

Only some participants took advantage of the timeline technique and the shared research diary, while others decided to focus solely on the spoken dialogue during the research interviews. We also conducted interviews with the primary caregivers of each participant. After consent was obtained at the beginning of our cooperation, all three interviews were audio-recorded for later transcription and coding. We used examples of the interview transcripts and field notes to illustrate the results of the analysis. A total of three researchers cooperated closely on the data collection. All the names and personal details of participants were changed to ensure the participants' anonymity.

\section{Participants}

The study is based on three repeated interviews with ten older adults, male and female, that were conducted over the course of one year and on their shared research diaries. All the participants came from the Czech Republic and, except for one 67-year-old, were over the age of 70 (see Table 2). The average age of the final sample was 84 years. Although we deliberately refrained from assessing research participants with any tests or scales measuring cognitive impairment, frailty, selfmaintenance abilities, or the instrumental activities of daily living, we can conclude that they all suffered from an acquired impairment that was permanent, irreversible, and dynamic and that significantly affected mostly their mobility functions. Most of the participants were immobile as a result of arthritis, osteoporosis, a previous fall or fracture, or general frailty. These chronic and persistent conditions were in some cases combined with other illnesses. In discussion with their formal or informal caregivers, the participants were identified as cognitively healthy people of advancing age who are - owing to involutional changes and impairment - unable to perform everyday activities independently (e.g. bathing, showering, transportation, managing their medication). Because of their impair- 
Table 2. Characteristics of participants and description of the context of care $(\mathbf{N}=10)$

\begin{tabular}{lc}
\hline & $\mathrm{N}$ \\
\hline Women & 8 \\
Men & 2 \\
Average age & 84 \\
Aged 65-70 & 2 \\
Aged 71-85 & 3 \\
Aged 86 + & 5 \\
Married & 2 \\
Widowed & 8 \\
Living in a nursing home & 7 \\
At home with a care professional & 2 \\
At home with an informal care-provider & 1 \\
Total number of participants & 10 \\
Total number of interviews with caregivers & 9 \\
Number of completed interviews with participants & 27 \\
\hline
\end{tabular}

ment, all the participants receive personal disability payments to support their daily living and mobility needs. One potential participant passed away before we could conduct the first interview and one participant died before we were able to complete the third interview. In these cases, we also did not conduct planned interviews with the participants' caregivers. The state of one participant was so unstable that we were not able to complete either the second or third interview.

\section{Data analysis}

In analysing the research questions, we focused mainly on the transcripts of the individual interviews with research participants that served as a primary data source (see Table 2). However, we also took into consideration the materials from the shared research diary and field notes [Emerson, Fretz and Shaw 1995]. All the materials were analysed using Atlas.ti software. The data analysis was performed in several steps and was influenced by the constructivist approach to grounded theory [Charmaz 2014] and some ethnographical principles [Charmaz 2014: 35; Esterberg 2002]. This approach allowed us to seek detailed knowledge of the multiple dimensions of life in transition from the third to the fourth age and to pay attention to the specific setting in which care is received. 
The process of data analysis involved a three-step coding procedure [Charmaz 2014]. We began with line-by-line open coding, as it helped us to identify the main categories that seemed to capture the most salient meanings of the body in the participants' narrations. In this step, we followed the initial coding and investigated the links and connections that could be built between the categories. The resulting codes were provisional, comparative, and grounded in the data. Some of them were reworked later in the process of focused coding. In general, we used the codes that were the most significant and frequently recurring. Many of them already indicated possible answers to our research questions. The last step was axial coding, which helped us to relate categories and subcategories, rework the dimensions of the categories, and make the working model coherent. In this phase, an analytical framework started to emerge from the data [Charmaz 2014].

Later, during the process of theoretical coding, we specified the relations between the categories developed in the step of focused coding and existing theoretical concepts. Some theoretical concepts served as sensitising concepts for our analysis and inspired the resulting working model. The sensitising concepts were understood as general concepts, ideas, or perspectives that directed our attention to certain phenomena or aspects of the phenomena and allowed us to differentiate more sensitively between different categories and subcategories [Strauss and Corbin 1990]. They represented effective tools with which to stimulate the whole analytical process [Bowen 2006; Charmaz 2014]. During these processes, we used memo-writing, which assisted us in capturing the thoughts, comparisons, and connections we made during the analysis. The memo notes also further crystallised the research questions. The findings of the analysis are structured according to the main analytical category and are related to the research questions dealing with the understanding of the body in transition from the third to the fourth age. No ethical approval was required to carry out the study in the Czech Republic.

\section{Findings}

The meanings that the participants ascribed to the body are captured and further described in the central category 'Embodiment in Action', which reconnects all the findings. Constantly changing embodiment is one of the key topics through which participants narrated their everydayness.

\section{Embodiment in Action}

The constantly changing meanings of the body are understood by the participants not solely as a predictable biological decline or a sharp decrease of functions pointing to the complete disappearance of agency both in relation to self and the surrounding world [Gilleard and Higgs 2010]. In the participants' narra- 
Table 3. An overview of the findings

\begin{tabular}{llll}
\hline $\begin{array}{l}\text { Dimensions } \\
\text { of Embodiment } \\
\text { in Action }\end{array}$ & $\begin{array}{l}\text { Emotional } \\
\text { aspects }\end{array}$ & Social aspects & Behavioural aspects \\
\hline $\begin{array}{l}\text { The Body as } \\
\text { the Organiser } \\
\text { of Activities }\end{array}$ & $\begin{array}{l}\text { Tension, } \\
\text { Uneasiness, } \\
\text { pride }\end{array}$ & $\begin{array}{l}\text { The importance } \\
\text { of relational } \\
\text { autonomy }\end{array}$ & $\begin{array}{l}\text { Approaching the body with } \\
\text { sensitivity } \\
\text { Distancing from the disciplined } \\
\text { body } \\
\text { Identifying with the body } \\
\text { of older 'role models' }\end{array}$ \\
$\begin{array}{l}\text { The Body as } \\
\text { an Uncertain }\end{array}$ & $\begin{array}{l}\text { Fear, } \\
\text { aggravation, } \\
\text { helplessness }\end{array}$ & $\begin{array}{l}\text { The importance } \\
\text { of temporal } \\
\text { social fatigue }\end{array}$ & $\begin{array}{l}\text { Active disengagement } \\
\text { Separating the parts of the body } \\
\text { that bear uncertainties } \\
\text { Management of fatigue }\end{array}$ \\
$\begin{array}{l}\text { The Body as Work } \\
\text { to be Done }\end{array}$ & $\begin{array}{l}\text { Sadness, } \\
\text { frustration, } \\
\text { calm, } \\
\text { ease }\end{array}$ & $\begin{array}{l}\text { Organising habits into a routine } \\
\text { of care received } \\
\text { from others }\end{array}$ & $\begin{array}{l}\text { Adapting to assistive devices } \\
\text { Overcoming limits through } \\
\text { activity }\end{array}$ \\
& & $\begin{array}{l}\text { Embodied imagination and } \\
\text { Remembering }\end{array}$ \\
\hline
\end{tabular}

tives, the body meanings are rather described as dynamic and constantly changing in many possible ways, while emphasising both the ups and downs that are understood in the short-term context.

The analysis revealed that the participants reconsidered the possibilities and limitations of the body during most of the everyday actions they described. For them bodily movements were represented by both physical and mental activities that require both physical and mental energy. In the case of walking, for example, they continuously evaluated optimal and safe motor performance. In the following example, 99-year-old Jaroslava describes her daily morning experience of walking to the kitchen, taking and counting the steps to get there as a time-consuming activity:

Can you imagine how much time it takes me to get up at 7 am and get to the kitchen? In my situation, it takes me at least an hour. First, I need to get to the bathroom, then I need to come back to the bedroom and get dressed. This is a demanding job for me. Moreover, this whole task includes steps! And I need to think about how to take them safely. (Jaroslava)

Constant negotiations have to be made in advanced between mental actions and physical actions in order to develop and sustain connections to the physical en- 
vironment, personal routines, and social networks. These negotiations are one of those processes that keep embodiment in constant action.

The central category, 'Embodiment in Action', therefore also captures the changes to embodiment that are described in participants' narratives as an experienced presence that is often compared with the past embodied experience, the anticipated future, or an optimal current state. The meanings of this category are shaped and reconstructed on at least three dimensions that capture processes such as: (1) the sensing of the body (the Body as the Organiser of Activities); (2) anticipation of the body (the Body as an Uncertain Companion); and (3) the managing of the body (the Body as Work to Be Done) (Table 3). The dimensions of the central category affirm that the body and mind in the narratives of participants do not represent detached components but instead form an interconnected, linked, and inseparable entity. Within these dimensions, participants have a varying degree of agency which, due to the circumstances of the physical and social environment and the conditions of social and health care, affects the resulting meanings of the body for the actual participant in a specific moment of his or her life.

\section{The Body as the Organiser of Activities}

The meanings of embodiment in action that were recorded in reference to the dimension of sensing are established on the basis of comparisons between past embodied experience and the current perception of embodiment in action. In the narratives, participants describe how they relate to their body in a sensitive and responsive way, which often contrasts with how they describe their previous attitudes. They claim previously to have paid less or no extra attention to the body, while today they are almost constantly aware that their everydayness is organised by their body together with their mind. This shift could be understood as a shift towards the framework of 'harmonious ageing', which is based on an integrated body and mind relationship [Liang and Luo 2012; Sandberg 2013]. Viewed in this way, the meanings of the 'Body as an Organiser of Activities' is accompanied by a description of a whole range of emotional experiences, such as tension, uneasiness, and pain, as well as pride [e.g. Grenier 2008].

In the narratives, the body is not understood merely as a constraint on wishes. As noted by 83-year-old Beata, whose body is rather fragile and whose ability to move around at home is limited, the body somehow calls for or determines every activity and inactivity during her day. Before the second interview, she wrote in the shared research diary that her body, mind, and memory are in constant interplay: 'Life at an advanced age is fine. My mind and memory have adapted to the possibilities of my body. I am lucky - I have a wonderful family.'

Despite the descriptions of the body as the organiser of everyday activities, social relationships also seem to strongly inform the sensation of the body's 
meanings. One reason why these social bonds are emphasised may be that the participants' lives are saliently affected by the context of care received from others, so they recognise and appreciate the importance of relational autonomy [Petrová Kafková and Sedláková 2017]. Some of these relationships are formed in everyday interactions with family and caregivers, while other ties are carried over from important experiences and memories. The perception of the 'Body as the Organiser of Activities' happens to a large extent within the power of significant others and within the possibilities of the relational autonomy.

Other important behavioural aspects attached to the meanings of the body that we recorded on the dimension of sensing included the process of participants distancing themselves from the bodies of their nursing home's clients, which are described as disciplined, and identifying with the representations of the bodies of older 'role models'. In this sense, Sofia, for whom the body represents the organiser of her daily activities, emphasises in her narrative that she maintains a distance from those older adults who allow their various activities to be totally ruled by the nursing home's employees [e.g. Townsend, Godfrey and Denby 2006]. On the contrary, she talks about the importance of reconnections with the body.

Each one of us just has to adapt to herself and her own possibilities. But in those 'Altersheim' places, where they organise activities for all the clients at the same time, it's fine, but... it's not the real thing. It's not what my and their bodies call for. I exercise for ten minutes every day and I would know it immediately if I forgot about those ten minutes one day. I'm that sensitive to my back and legs. (Sofia)

Jaroslava, on the other hand, questions the representations of centenarians whose bodies do not show any signs of weakness:

Well, that's how I live now. I don't believe it when they show those 100-year-old people on television just going out walking, so fresh and fit. No, that can't be true. Every one of us has something to be concerned about. Sometimes it just hurts here or there all the time. (Jaroslava)

Unlike these cases, participants identify with some of the representations of older role models' bodies, such as Queen Elizabeth II or the Pope. They seem to class them as their age peers and idols because they have managed to keep going regardless of their perceived physical limitations [José 2016; Townsend, Godfrey and Denby 2006]. By emphasising the similarities, they are partially normalising the meanings of the body as the organiser of everyday activities, as part of Beata's narrative reveals: 'I always think about the difference between what the British Queen does during the day and what I do. Well, I say to myself, she is three years older, so it's probably not as good as she might have wished. But, like myself, she probably needs to listen to her body all the time.' 


\section{The Body as an Uncertain Companion}

The meanings of embodiment in action recorded on the dimension of anticipation, illustrate the participants' understanding of the Body as an Uncertain Companion. In their narratives, participants describe the body as unreliable and temporarily unstable. These meanings are established on the basis of comparisons between the present embodied experience and the anticipated future. In the parts of the narratives that relate to the meanings of the Body as an Uncertain Companion, the participants often mention experiencing feelings of fear [e.g. Grenier 2008]. In this context, they also emphasise feelings of aggravation towards their body, which is not functioning the way that they would expect it to. The participants mention this feeling, for example, when narrating their experiences of dizziness and fainting spells, which sometimes result in a loss of control over the body, as 99-year-old Jaroslava's narrative reveals: 'I often feel that I'm losing control. There is just this dizziness, when I feel like fainting ... I faint and it's impossible to describe or somehow avoid it. I fall without any control. Well, that's what I fear, how I live now.' Feelings of uncertainty and fear about not being able to control her own body are even deeper in Jaroslava's consciousness: 'I just can't lift my body. I literally can't lift it, because of old age, I have become so weak that I simply can't.' Awareness of this uncertainty leads Jaroslava to adopt some routine measures (e.g. not turning off the lights while watching TV ...) in order to minimise risks.

Temporary states of fatigue and weakness are other important aspects of the meanings of the 'Body as an Uncertain Companion'. Participants talk about experiencing an overall slowing down process [Lloyd et al. 2014]. The presence of tiredness is often connected to feelings of helplessness, which were repeatedly mentioned by, for example, by 86-year-old Beata in her shared research diary: 'I feel tired almost all the time, but I can't do anything about it.' In their narratives, the participants further describe the requirements for both physical and mental rest and emphasise the experiences of social fatigue that represent the main social aspect of the meanings of the 'Body as an Uncertain Companion'. For many participants, the active disengagement from physically or socially demanding situations is an actively followed choice and therefore also the expression of their agency, which can be overlooked as a sign of resistance [José 2016; Lloyd et al. 2014; Nicholson et al. 2012]. Such a situation is described by 95-yearold Hana: 'I'm terribly tired after every visit of my granddaughter because of her little son and daughter. It just takes me too much energy to be in their company, even when it's just for a while. I certainly know what amount of time spent with them is suitable for me.'

Another important behavioural aspect of the 'Body as an Uncertain Companion' is the management of tiredness. This kind of management takes the form of constant negotiations that result in the development of a useful schedule that respects the unique possibilities and limitations of each person. The efforts to create such a schedule are strongly present in some of the notes that participants 
wrote in the shared research diaries. In their narratives, participants talk about protecting themselves from feelings of uncertainty by planning and designing an organised routine. They describe how these routines consist of deeply ingrained habits - for example, as described in one excerpt from Hugo's narrative: ' ... almost everything has become a habit for me, so I do everything systematically and according to these habits' [e.g. Lloyd et al. 2014]. Jaroslava also describes the fundamental importance of habits in her life: ' ... I have a piece of Christmas cake for breakfast every morning. Every day. Because first I got used to it, and I have to do everything systematically. If I don't, so to speak, I'll break the wheels and can't live that day, as I always do when I don't do the same'. For both Hugo and Jaroslava, a regular daily routine is an effective strategy with which to compensate for the uncertainty associated with their own corporeality. Designing an organised routine therefore 'anchors' the participants in their everydayness, marked with numerous moments of uncertainty.

Participants also state that they feel frail rather than that they are frail. In the narratives, the participants distinguished the 'problematic' parts of the body that are the source of this uncertainty (e.g. knees, joints) from their overall perception of the body, as described in the excerpt from Sofia's narrative:

These knees are holding me back. These knees and their problems. They've caused me a lot of changes. ... These knees are making me sick. They're making me angry. These knees are bad enough to me, well and they are all that I'm afraid of. What the hell will I do with these knees? (Sofia)

Similarly, Dana can no longer sew because 'my knees don't work' and 'I can't thread the needle with my fingers anymore'. It is not her but her body parts that are making it impossible for her to live the way she was used to. We can talk about the alienated body that cannot be properly controlled [Galčanová and Petrová Kafková 2018]. In their narratives, they further talk about having a frail body, rather than being frail, which would be a totalised identity [Grenier 2006; Nicholson et al. 2012], a label that becomes their only identity and that in the eyes of others overshadows everything else and identifies them as ageing subjects in need of care. In a way, feelings of frailty may to them represent the emotional aspects of their experiences of impairment in later life. However, participants place strong emphasis on the temporality of these states, which repeatedly alternate with states of greater strength. In their narratives, the theme of the 'Body as an Uncertain Companion' was linked back to the demands of self-management. In their descriptions of activities associated with self-management, the participants alternated between a tendency towards endurance and feelings of temporary exhaustion. Such cyclical descriptions of states are reminiscent of the systolic and diastolic rhythm. 


\section{The Body as Work to Be Done}

The meanings of embodiment in action that were recorded on the dimension of managing are established on the basis of comparisons between the present time and present needs and the optimal present time in which the needs are met. In the narratives, participants describe the body as a work that requires the salient attention necessary for the course of everyday life. In this sense, they talk about the body both as work that needs to be done - 'I must always get up and take care, no matter whether I have slept well or badly' - and as a sort of 'cage' that does not allow them to express everything they intend to in relation to the surrounding world and others:

I'd like to be dressed suitably for my age but still look pretty. However, I don't have the opportunity to buy or wear anything nice. I absolutely can't, even if I just wanted a simple tracksuit. It's impossible to get one for my body. (Jaroslava)

The participants experience the body and its limits both as restrictive and as stimulating them into action - for example, through prevention, care with assistive devices.

The meanings of the 'Body as Work to Be Done' relate to at least two types of embodied experience of limitations. In their narratives, the participants emphasise what their current limitations are and the limitations that could be understood as potential. Current limitations prevent them from participating in the activities they would like to be currently involved in. Such situations range from the simple activities as described by Jaroslava to the less frequent but important experiences described here by Tereza:

I can imagine it as vividly as if I was there right now. I'm sitting there on Chopok Mountain. I'm wearing boots on my feet. There are views on the left side, views on the right side, beautiful views all around. That space. That outlook. That freedom. It's me ... the same Tereza I used to be before, but my body is now 83 years old and I'm no longer able to reach the peak of Chopok. (Tereza)

For example, the first experiences are described through episodes of cramps that prevent activities such as eating with a spoon, doing a crossword puzzle, or peeling an apple, as Jaroslava's narrative reveals: 'I was peeling an apple and holding a knife, when I suddenly got cramps in my hand. It was just before lunch when the cramps caught me. During lunch, the spoon kept falling from my hand. I couldn't even eat lunch, but I simply had to. Who else was going to put it in my mouth?'

In his study, Whitaker [2010] mentions feelings of sorrow, grief, distress, shame, embarrassment, humiliation, indignity, and frustration that are connected to the perception of an incapable body. Similarly, participants describe the feelings of 'sadness' and 'frustration' in connection with the 'Body as Work to Be Done', which we can see in an extract from Dana's narrative: 'Sometimes I like 
to cry about my body, I cry repeatedly. I can't even tie a knot.' Sadness, however, sometimes results in a catharsis, bringing about feelings of 'calm' and 'ease'.

The second type of limiting experiences are negotiated between the participants and 'experts' such as doctors, nurses, and caregivers. In the view of the participants, not respecting potential limitations is risky and could lead to an undesirable future, which is represented by the feared state of having a completely incapacitated body [e.g. Higgs and Gilleard 2015]. Therefore, it is necessary rather to avoid certain types of 'risky behaviour', such as walking unaccompanied by others, lifting heavy objects, or the consumption of alcohol and fatty meat. Descriptions of potential limitations are often preceded by unpleasant dizziness or flashes of sudden pain. These moments are called 'time bombs', as participants often do not know the cause of them, and this produces extra uncertainty, as Jaroslava's narrative shows: 'You can feel pain anywhere and anytime. I experience it terribly often. I wonder what it can be, I wonder if it'll go away a moment later or ... the experience will be repeated again, only God knows when.'

In situations where the participants daily face both types of limiting experience, the acceptance of the care that is received becomes an important social aspect of 'Embodiment in Action' and a crucial prerequisite for living and for being able to reconnect with the surrounding world [Higgs and Gilleard 2015]. As narrated, the acceptance of psychological, social, and material help is the result of continual negotiations between what the participants want and need and what they can achieve within a certain context on their own.

Participants relate to the 'Body as Work to Be Done' in at least three ways that can be understood as behavioural aspects of these body meanings: (1) adapting to assistive devices, (2) overcoming limitations through activity, and (3) embodiment imagination and remembering. In the participants' narratives, the body is described as fused with these devices and as empowered through technological devices and extensions, such as mobility aids (e.g. walkers, canes, crutches, wheelchairs, orthotic devices), hearing aids, visual aids, or dental prostheses. Among these devices, we could possibly include some other items necessary for a life with acquired impairment in advanced age, such as 'a miraculous medical armchair' or 'a bed-my-helper with raised handles'. Assistive devices are described by participants as 'the extended and helpful parts of the body'.

For participants, assistive devices become an adopted part of the body and one way not only of compensating for physical impairments but also of dealing with the uncertainties of daily living. Participants do not avoid talking about assistive devices; they describe them with words such as 'my' or 'my only', use diminutives, and employ language that is personal and intimate, as Hugo's narrative shows:

I'm going to finish my life with my great sticks. I have this great one and then also an even better stick. I just don't know right now where I put it. I've probably left it in the toilet. I sometimes go there with it and then come back without it. Full of new courage. (Hugo) 
Participants take care of these devices much like they take care of their bodies. In her narrative, 84-year-old Tereza describes how she, in her free time, repairs her hearing aid and checks whether the batteries need to be charged, so as to avoid periods of disruption to her communication. Similarly, Sofia, with the help of her son, has invented new ways of improving her walker to suit her current needs and enable more flexible body movements:

R: Looking at it right now, I can see that you have a stick stuck to the walker. Why? My son just recently stuck the stick to the walker. When I want to go to the room to socialise, I go there with the walker, but to flexibly walk around the room I need the stick. So, we just stuck it there and now I have both. [laughs] When I have my stick there, I just take it from the walker and move about better. Although my walker is a much better help everywhere else. (Sofia)

In the narratives, the participants often mention that the devices make life more predictable, although some devices may be unreliable in a specific context - for example, on a slippery surface or in a darker environment.

In the narratives, participants often describe that they further relate to the 'Body as Work to Be Done' by overcoming limitations through a focus on activities in the area of care work [e.g. Twigg 2004; José 2015]. In their narratives, such behaviour is most obvious in the frequently use of words such as 'must', 'need to', 'have to', etc. Such an approach may be understood as a way of preventing any failure that might cause them bigger 'problems' in the near future [Rudman 2015]. For example, Sofia and Tereza describe not wanting to use a wheelchair, even though it would be easier for them. However, to them it would also mean that the body could get used to it and they might never go back to using the walker and stick again. The wheelchair is a symbol of decline into greater impotence, confirming the deterioration of their health. For this reason, both participants emphasise the need for regular exercise to delay this deterioration. It is about taking responsible control over their body, which is one of the consequences of the social pressure to be active. They use only the assistive devices that are indispensable, as Tereza describes in her narrative:

During morning exercises, my joints are relaxed and become much easier to move. I try hard because I have to. My hands are stiff in the morning. I can straighten this one, but I have to exercise the other one when I wake up. Every morning I stretch my legs, even my fingers. Many times. I imagine that if someone entered my room and found me exercising here, they'd think I'm crazy. [laughs] (Tereza)

In the understanding of participants, a focus on activities in the area of care work seems to be one of the ways of not 'becoming a burden on others'.

The third behavioural aspect of the 'Body as Work to Be Done' relates to the body through 'embodied imagination and remembering' as this excerpt from Tereza's narrative shows: 
I'm sitting there on the bed with my pants around my knees. My body is there, but I'm listening. I'm listening to the music like never before. Goosebumps all over my body. And I totally forget that I should be getting dressed instead. I'm just being, and I say to myself: It's the same you, Tereza. (Tereza)

This process may at the same time be a way of affirming the continuity of one's identity. It could be a way for them to confirm that their identity is not based solely on disability and age, and a way for them to confirm that they are not just clients of the care home, but, despite the occasional use of a wheelchair, are still the same women they used to be.

\section{Discussion}

This paper summarises the knowledge about transitions in old age that are currently organised along different lines of experience than age. One such experience is that of acquired impairment that may be dynamic in nature, may occur earlier than expected, and may involve moments of recovery and re-occurrence [Grenier 2015]. The paper considers the transitions in the context of current theories of the fourth age that take place at the intersection of the body and ageing [Baltes and Smith 2003; Grenier, Lloyd and Phillipson 2017; Higgs and Gilleard 2016].

Until recently, issues concerning the marginalised or 'problematic' ageing body were avoided in social gerontology [Öberg 2003; Shilling 2007; Twigg 2006]. The authors of this study are aware of the danger of stereotypical images of older people's bodies as simply dependent, frail, and declining [Twigg 2004; Gullette 2004]. However, we consider ageing to be a deeply embodied process and therefore stress that the bodily aspects of ageing cannot be ignored but must be understood and interpreted as part of the complex social, cultural, emotional, and material reality of ageing [Grosz 1994; Meier et al. 2012; Sandberg 2013].

The aim of this study is to examine the meanings of the body during the transitions in old age. This has remained a relatively under-researched field. Drawing on an analysis of personal accounts collected through individual interviews and shared diaries conducted with a sample of respondents over the course of one year (8 women, mean age -83.8 years), our research also sought to investigate the ways in which people relate to meanings of the body within a context where they are recipients of care. The findings are relevant not only from a gerontological viewpoint, as they extend our knowledge of life at an advanced age, but also from the viewpoint of public policy and practical care. These findings may help in the development of useful interventions to promote more dignified and mindful approaches in the sphere of social and health care.

We gathered the answers to our main research question in a central category called 'Embodiment in Action'. The findings suggest that changes to the body in the direction of decline are understood as inevitable. However, beyond these 
accounts of decline, the participants in our research described an extensive and highly dynamic network of complex meanings of the body. In the participants' narratives, the social, emotional, and behavioural aspects of the body's meanings are considered to be just as relevant the body's biological aspects. Moreover, according to participants, embodiment changes do not occur in just one direction, in the direction of long-term loss and decay but are instead understood in shorter time segments and described as occurring in different directions. The meanings of 'Embodiment in Action' were found to be shaped and reconstructed on dimensions that capture three important processes: the sensing of the body (the 'Body as the Organiser of Activities'), anticipation of the body (the 'Body as an Uncertain Companion') and the managing of the body (the 'Body as Work to Be Done'). In the fourth age the body becomes a central entity in a person's life [Whitaker 2010], the entity around which one's whole life is centred. It is a means of communication, and a means of experiencing pain and care. The concept of embodiment acquires a new meaning in the fourth age. The body becomes both an enabler and a limiter of each and even the smallest everyday activity. It is both an agent and a limit.

The meanings of embodiment in action, gathered on the dimension of sensing, are established on the basis of comparisons between people's embodied experience in the past and their current perception of embodiment in action. The disabled body is a marker of failure in later life, the failure to accomplish successful ageing. The main social aspect of the 'Body as the Organiser of Activity' is the importance of relational autonomy [Petrová Kafková and Sedláková 2017], while the feelings of tension and unease about the body are emotional [Grenier 2008] and are approached with greater sensitivity than ever before. This could be understood as a shift towards 'harmonious ageing' [Liang and Luo 2012; Sandberg 2013]. In their narratives, the participants mentioned that they relate to the body by distancing themselves from the disciplined body [Katz 2000]. They further identify the body with representations of the bodies of older 'role models', who represent heroes to them [Townsend, Godfrey and Denby 2006].

The meanings of embodiment in action that are gathered on the dimension of anticipation are centred on a sense of anticipated uncertainty. The main social aspects of the 'Body as an Uncertain Companion' involve frequent experiences of social fatigue. Its emotional aspects are the feelings of fear, aggravation, and helplessness about the body [Grenier 2008]. In their descriptions of the 'Body as an Uncertain Companion', participants emphasise that they often actively choose to disengage from demanding situations [José 2016; Lloyd et al. 2014; Nicholson et al. 2012]. They also describe other approaches they apply to these meanings of the body, such as differentiating those body parts that are a source of uncertainty, managing their tiredness, and organising a routine of habits [e.g. Lloyd et al. 2014].

The meanings of the body that are gathered on the dimension of managing relate to descriptions of the actual and potential limitations of the body. The 
emotional aspects of these body meanings are feelings of sadness and frustration, as well as feelings of calm and ease [e.g. Whitaker 2010]. The main social aspect of the 'Body as Work to Be Done' is the acceptance of received care that becomes the basic condition of connection to the surrounding world [Higgs and Gilleard 2015].

These meanings of the body are approached in at least three important ways: adapting to assistive devices; overcoming limits through activity [José 2015; Rudman 2015], and embodied imagination and remembering. Findings suggest that the meanings of the body play a key role in the transitional processes in old age. The complex nature of the meanings associated with the body meanings should be recognised in practices of care.

\section{The study's limitations and future research directions}

We are aware that more attention could be paid to a multimethod approach and the use of techniques focusing on non-verbal behaviour. In our study, we used field notes from our observations as supplementary data [Esterberg 2002]. Given the wealth of data, it would be useful to extend this ethnographic observation. Another limitation is the impossibility of using care documents that could provide researchers with a long-term framework. Our study also suffers from the fact that it takes only partial account of the perspectives of caregivers, which could enrich the picture provided by the testimony of participants, shed more complex light on them, and serve as one form of validation of the constructionist method of analysis [Charmaz 2014]. Further limitations are related to the social constructionist approaches to embodiment. According to some authors [e.g. Williams and Bendelow 2002], some aspects of the ageing body captured through the social constructionist perspective leave the materiality of impairments and bodies undocumented. To capture the lived experience of the body, one should adopt a more phenomenological stance. For further studies, it would also be appropriate to have a stronger interdisciplinary link with disability studies.

Further research in this field could focus on the ethnographic understanding of communication between older adults and their caregivers, and how the body is negotiated in these types of conversations. Studies could also focus on those micro-areas of care that are key to the lives of persons with acquired impairment in later life (e.g. rehabilitation through walking, adaptation to assistive devices). Within the context of care, ageing persons need to be treated with respect by others and need to be able to exercise control over their autonomy, even when they are partially dependent on others. A future study could pay more attention to exploring embodiment and the methods of preserving dignity. 


\section{Conclusion}

In this paper, we sought to show that research on people transitioning from the third to what is called the fourth age is both possible and important and results in valuable knowledge that leads to a better understanding of the neglected and feared parts of the human life cycle. In contemporary societies, later life may have lost much of the coherence and predictability that characterised it in the past. Instead, diversity, difference, and inequality have become its more salient features. As social gerontologists and researchers in the field of ageing studies, in our approach to this study we tried to avoid the quicksand of binary reflections on polarised images of old age. In a binary perspective on the third and fourth age, or on a healthy or fragile old age, the latter of the two categories is defined in terms of being unsuccessful, as failing. The fourth age, or fragile old age, is portrayed as something we all want to avoid - a black hole that once descended into people cannot return from, a place where the actor is no longer allowed any action [Gilleard and Higgs 2010]. Our text shows that the boundaries within the experience of old age are much more complex, unclear, and fluid, and much more heterogeneous.

TATIANA SEDLÁKOVÁ was a PhD student of social psychology at the Faculty of Social Studies, Masaryk University in Brno when she was writing this paper. She is interested in the issues and controversies associated with ageism, intergenerational relationships, and individual ageing, especially transitive processes in older age, changes in memory functions, and the consequences of these changes on self-perception.

Marcela Petrová KafKOvá is a sociologist and researcher at the Department of Sociology, Masaryk University. Her long-term research interests are the sociology of ageing and social gerontology. Her research concentrates on the issues of active ageing, social exclusion, ageing with disabilities, and the environmental determinants of ageing.

\section{References}

Adriansen, H. K. 2012. 'Timeline Interviews: A Tool for Conducting Life History Research.' Qualitative Studies 3 (1): 40-55, https://doi.org/10.7146/qs.v3i1.6272.

Baltes, P. B. and J. Smith. 2003. 'New Frontiers in the Future of Aging: From Successful Aging of the Young Old to the Dilemmas of the Fourth Age.' Gerontology 49 (2): 123-135, https://doi.org/10.1159/000067946.

Bowen, G. A. 2006. 'Grounded Theory and Sensitizing Concepts.' International Journal of Qualitative Methods 5 (3). Retrieved 15 June 2021 (http:// www.ualberta.ca/ iiqm/ backissues/5_3/pdf/bowen.pdf), https://doi.org/10.1177/160940690600500304. 
Charmaz, K. 2014. Constructing Grounded Theory: A Practical Guide through Qualitative Analysis. London: Sage Publication.

Clarke, L. H. and A. Korotchenko. 2011. 'Ageing and the Body: A Review.' Canadian Journal on Ageing 30: 495-510, https://doi.org/10.1017/S0714980811000274.

Clarke, L. H., E. V. Bennett and A. Korotchenko. 2014. 'Negotiating Vulnerabilities: How Older Adults with Multiple Chronic Conditions Interact with Physicians.' Canadian Journal on Aging 33 (1): 26-37, https://doi.org/10.1017/S0714980813000597.

Emerson, R. M., R. I. Fretz and L. L. Shaw. 1995. Writing Ethnographic Fieldnotes. Chicago, IL: University of Chicago Press, https://doi.org/10.7208/ chicago/9780226206851.001.0001.

Esterberg, K. G. 2002. 'Observation: Participant and Otherwise.' Pp. 58-82 in Qualitative Methods in Social Research, edited by K. G. Esterberg. Boston, MA: McGraw-Hill.

Featherstone, M. and M. Hepworth. 1991. 'The Mask of Ageing and the Postmodern Life Course.' Pp. 371-389 in The Body, Social Processes and Cultural Theory, edited by M. Featherstone, M. Hepworth and B. Turner. London: Sage, https://doi.org/10.4135/9781446280546.n15.

Featherstone, M. and M. Hepworth. 1989. 'Ageing and Old Age: Reflections on the Postmodern Lifecourse.' Pp. 143-157 in Becoming and Being Old: Sociological Approaches to Later Life, edited by B. Bytheway, T. Keil, P. Allatt and A. Bryman. London: Sage.

Galčanová, L. and M. Petrová Kafková. 'Self-Perception during the Transition to the Fourth Age in the Czech Republic.' Ethnologie Française (171): 413-426, https://doi.org/10.3917/ethn.183.0413.

Gilleard, C. J. and P. Higgs. 2010. 'Ageing without Agency: Theorizing the Fourth Age. Aging \& Mental Health 14 (2): 121-128, https://doi.org/10.1080/13607860903228762.

Gilleard, C. J. and P. Higgs. 2011. 'Ageing Abjection and Embodiment in the Fourth Age.' Journal of Aging Studies 25 (2): 135-142, https://doi.org/10.1016/j.jaging.2010.08.018.

Gilleard, C. J. and P. Higgs. 2013. 'The Fourth Age and the Concept of a "Social Imaginary": A Theoretical Excursus.' Journal of Aging Studies 27 (4): 368-376, https://doi.org/10.1016/j.jaging.2013.08.004.

Gilleard, C. J. and P. Higgs. 2014. Ageing, Corporeality and Embodiment. London: Anthem Press.

Grenier, A., L. Lloyd and C. Phillipson. 2017. 'Precarity in Late Life: Rethinking Dementia as a 'Frail' Old Age.' Sociology of Health and Illness 39 (2): 318-330, https:// doi.org/10.1111/1467-9566.12476.

Grenier, A. 2006. 'The Distinction Between Being and Feeling Frail: Exploring Emotional Experiences in Health and Social Care.' Journal of Social Work Practice 20 (3): 299-313, https://doi.org/10.1080/02650530600931849.

Grenier, A. 2012. 'Socio-cultural Constructs of Late Life.' Pp. 79-96 in Transitions and the Lifecourse: Challenging the Constructions of 'Growing Old', edited by A. Grenier. Bristol: Policy Press at the University of Bristol.

Grenier, A. 2015. 'Transitions, Time and Later Life.' Pp. 404-411 in Routledge Handbook of Cultural Gerontology, edited by J. Twigg and W. Martin. New York: Routledge.

Grosz, E. 1994. Volatile Bodies: Toward a Corporeal Feminism. Indianapolis, IN: Indiana University Press.

Gubrium, J. F. and J. A. Holstein. 2003. Ways of Aging. Malden: Blackwell Publishers, https://doi.org/10.1002/9780470756157.

Guenette, F. and A. Marshall. 2009. 'Time Line Drawings: Enhancing Participant Voice in Narrative Interviews on Sensitive Topics.' International Journal of Qualitative Methods 8 (1): 85-92, https://doi.org/10.1177/160940690900800108.

Gullette, M. M. 2004. Aged by Culture. Chicago, IL: University of Chicago Press. 
Heikkinnen, R. L. 2000. 'Ageing in an Autobiographical Context.' Ageing and Society 20 (4): 467-483, https://doi.org/10.1017/S0144686X99007795.

Heikkinen, R. L. 2004. 'The Experience of Ageing and Advanced Old Age: A Ten-Year Follow-Up.' Ageing and Society 24 (4): 567-582, https://doi.org/10.1017/S0144686X04001837.

Higgs, P. and C. J. Gilleard. 2015. Rethinking Old Age: Theorising the Fourth Age. London: Palgrave, https://doi.org/10.1007/978-1-137-38400-3.

Higgs, P. and C. J. Gilleard. 2016. Personhood, Identity and Care in Advanced Old Age. Bristol: Policy Press, https://doi.org/10.1332/policypress/9781447319054.001.0001.

Hilário, A. P. 2015. 'Making Sense of a Changed Physical Body: Why Gender Matters at End of Life.' Journal of Aging Studies 33: 58-66, https://doi.org/10.1016/j.jaging.2015.03.001.

Horgas, A. L., H. Wilms and M. M. Baltes. 1998. ‘Daily Life in Very Old Age: Everyday Activities as Expression of Successful Living.' The Gerontologist 38 (5): 556-568, https://doi.org/10.1093/geront/38.5.556.

Jolanki, O. 2009. 'Agency in Talk about Old Age and Health.' Journal of Aging Studies 23 (4): 215-226, https://doi.org/10.1016/j.jaging.2007.12.020.

Katz, S. 2000. 'Busy Bodies: Activity, Aging, and the Management of Everyday Life.' Journal of Aging Studies 14 (2): 135-152, https://doi.org/10.1016/S0890-4065(00)80008-0.

Laslett, P. 1991. A Fresh Map of Life: The Emergence of the Third Age. Boston, MA: Harvard University Press.

Liang, J. and B. Luo. 2015. 'Toward a Discourse Shift in Social Gerontology: From Successful to Harmonious Aging.' Journal of Aging Studies 26 (3): 327-334, https:// doi.org/10.1016/j.jaging.2012.03.001.

Lloyd, L., M. Calnan, A. M. Cameron, J. Seymour and R. Smith. 2014. 'Identity in the Fourth Age: Perseverance, Adaptation and Maintaining Dignity.' Ageing $\mathcal{E}$ Society 34 (1): 1-19, https://doi.org/10.1017/S0144686X12000761.

Meier, B. P., S. Schnall, N. Schwarz and J. A. Bargh. 2012. 'Embodiment in Social Psychology.' Topics in Cognitive Science 4 (4): 1-12, https://doi.org/10.1111/j.1756-8765.2012.01212.x.

Neugarten, B. L. 1974. 'Age Groups in American Society and the Rise of the Young-Old.' The ANNALS of the American Academy of Political and Social Science 415 (1): 187-198, https://doi.org/10.1177/000271627441500114.

Nicholson, C., J. Meyer, M. Flatley, C. Holman and K. Lowton. 2012. 'Living on the Margin: Understanding the Experience of Living and Dying with Frailty in Old Age.' Social Science \& Medicine 75 (8): 1426-1432, https:// doi.org/10.1016/j.socscimed.2012.06.011.

Nicholson, C., J. Meyer, M. Flatley and C. Holman. 2013. ‘The Experience of Living at Home with Frailty in Old Age: A Psychosocial Qualitative Study.' International Journal of Nursing Studies 50 (9): 1172-1179, https://doi.org/10.1016/j.ijnurstu.2012.01.006.

Öberg, P. 1996. 'The Absent Body: A Social Gerontological Paradox.' Ageing \& Society 16: 701-719, https://doi.org/10.1017/S0144686X00020055.

Öberg, P. 2003. 'Images versus Experiences of the Aging Body.' Pp. 103-139 in Aging Bodies: Meanings and Perspectives, edited by C. Faircloth. Walnut Creek, CA: AltaMira Press.

Petrová Kafková, M. and T. Sedláková. 2017. ‘Čtvrtý věk jako specifické pole pro vyjádření aktérství.' (The fourth age as a specific field for the expression of agency) Sociologický časopis/Czech Sociological Review 53 (5): 719-735, https://doi.org/10.13060/00380288.2017.53.5.362. 
Phinney, A. and C. A. Chesla. 2003. 'The Lived Body in Dementia.' Journal of Aging Studies 17 (3): 283-299, https://doi.org/10.1016/S0890-4065(03)00029-X.

Pirhonnen, J., H. Ojala, K. Lumme-Sandt and I. Pietilä. 2015. "“Old But Not That Old”: Finnish Community-Dwelling People Aged 90 Plus Negotiating Their Autonomy.' Ageing \& Society 36 (8): 1625-1644, https:// doi.org/10.1017/S0144686X15000525.

Rubin, H. J. and I. S. Rubin. 2005. Qualitative Interviewing: The Art of Hearing Data. Thousand Oaks, CA: Sage, https://doi.org/10.4135/9781452226651.

Rudman, D. L. 2015. 'Embodying Positive Aging and Neoliberal Rationality: Talking about the Aging Body within Narratives of Retirement.' Journal of Aging Studies 34: 10-20, https://doi.org/10.1016/j.jaging.2015.03.005.

Sandberg, L. 2013. 'Affirmative Old Age - the Ageing Body and Feminist Theories on Difference.' International Journal of Ageing and Later Life 8 (1): 11-40, https://doi.org/10.3384/ijal.1652-8670.12197.

Sao José, J. M. 2016. 'Preserving Dignity in Later Life.' Canadian Journal on Aging 35 (3): 332-347, https://doi.org/10.1017/S0714980816000398.

Sedláková, T. and A. Souralová. 2017. 'Emerging Age Asymmetries in the Research Relationship: Challenges of Exploring Transition to the Fourth Age.' Ageing and Society 39 (2): 409-433, https://doi.org/10.1017/S0144686X17001040.

Sheridan, J., K. Chamberlain and A. Dupuis. 2011. 'Timeline: Visualizing Experience.' Qualitative Research 11 (5): 552-569, https://doi.org/10.1177/1468794111413235.

Shilling, C. 2007. 'Sociology and the Body: Classical Traditions and New Agendas.' The Sociological Review 55: 1-18, https://doi.org/10.1111/j.1467-954X.2007.00689.x.

Strauss, A. L. and J. Corbin. 1990. Basics of Qualitative Research: Grounded Theory Procedures and Techniques. London: Sage.

Townsend, J., M. Dogfrey and T. Denby. 2006. ‘Heroines, Villains and Victims: Older People's Perceptions of Others.' Ageing and Society 26 (6): 883-900, https://doi.org/10.1017/S0144686X06005149.

Twigg, J. 2004. 'The Body, Gender and Age: Feminist Insights in Social Gerontology.' Journal of Aging Studies 18: 59-73, https://doi.org/10.1016/j.jaging.2003.09.001.

Twigg, J. 2006. The Body in Health and Social Care. New York: Palgrave Macmillan, https://doi.org/10.1007/978-1-137-02143-4.

Whitaker, A. 2010. 'The Body as Existential Midpoint - the Aging and Dying Body of Nursing Home Residents.' Journal of Aging Studies 24 (2): 96-104, https://doi.org/10.1016/j.jaging.2008.10.005.

Williams, S. J. and G. A. Bendelow. 2002. The Lived Body: Sociological Themes, Embodied Issued. London: Routledge. 